\title{
Revascularization in multivessel disease: Comparison between two-year outcomes of coronary bypass surgery and stenting
}

Felix Unger, MD, MDhc ${ }^{a}$

Patrick W. Serruys, MD, PhD ${ }^{b}$

Magdi H. Yacoub, MB, FRCP, FRCS, FRS, KBE

Charles Ilsley, MD, MB, FRCP, FRACP ${ }^{\mathrm{C}}$

Peter Kildeberg Paulsen, MD, DMSc ${ }^{d}$

Torsten Toftegaard Nielsen, MD, DMSc ${ }^{d}$

Leon Eysmann, MD, $\mathrm{PhD}^{\mathrm{e}}$

Ferdinand Kiemeneij, MD, $\mathrm{PhD}^{\mathrm{c}}$

From the Klinik ruer Herzchirurgie, Landeskliniken Salzburg, Austria, ${ }^{\mathrm{a}}$ Thoraxcenter, Erasmus Medical Center Rotterdam, Rotterdam, The Netherlands, ${ }^{\text {b }}$ Harefield Hospital, Uxbridge, Middlesex, United

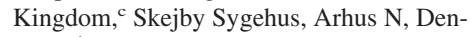
mark, ${ }^{\mathrm{d}}$ and Onze Lieve Vrouwe Gasthuis, Amsterdam, The Netherlands. ${ }^{\mathrm{e}}$

Received for publication July 27, 2001; revisions requested Sept 10, 2001; revisions received Nov 38, 2001; accepted for publication Jan 10, 2002.

Address for reprints: Professor F. Unger, MD, MDhc, Klinik fuer Herzchirurgie, Landeskliniken, Muellner Hauptstr. 48, A-5020, Salzburg, Austria (E-mail: f. unger@lks.at).

J Thorac Cardiovasc Surg 2003;125:809-20

Copyright $(\odot 2003$ by The American Association for Thoracic Surgery

$0022-5223 / 2003 \$ 30.00+0$

doi: $10.1067 / \mathrm{mtc} .2003 .401$
Objective: The recent appreciation that stenting has improved the short- and longterm outcomes of patients treated with coronary angioplasty has made it imperative to reconsider the comparison between surgery and percutaneous interventions in patients with multivessel disease.

Methods: One thousand two hundred five patients were randomly assigned to undergo bypass surgery or angioplasty with stent implantation when there was consensus between the cardiac surgeon and interventional cardiologist as to equivalent treatability. The primary clinical end point was freedom from major adverse cardiac and cerebrovascular events at 1 year. Major adverse cardiac and cerebrovascular events at 2 years constituted a secondary end point.

Results: At 2 years, $89.6 \%$ of the surgical group and $89.2 \%$ of the stent group were free from death, stroke, and myocardial infarction (log-rank test $P=.65$ ). Among patients who survived without stroke or myocardial infarction, $19.7 \%$ in the stent group underwent a second revascularization, as compared with $4.8 \%$ in the surgical group $(P<.001)$. At 2 years, $84.8 \%$ of the surgical group and $69.5 \%$ of the stent group were event-free survivors (log-rank test $P<.001$ ), and $87.2 \%$ in the surgical cohort and $79.6 \%$ in the stent group were angina-free survivors $(P=.001)$. In the diabetes subgroup, $82.3 \%$ of the surgical group and $56.3 \%$ of the stent group were free from any events after 2 years (log-rank test $P<.001)$.

Conclusion: The difference in outcome between surgery and stenting observed at 1 year in patients with multivessel disease remained essentially unchanged at 2 years. Stenting was associated with a greater need for repeat revascularization. In view of the relatively greater difference in outcome in patients with diabetes, surgery clearly seems to be the preferable form of treatment for these patients.

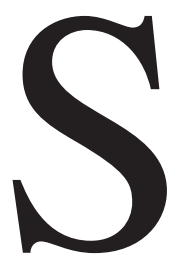

tenting has had a significant impact on coronary revascularization. The volume of stented angioplasty has exceeded all expectations and is more than the volume of cardiac surgery. ${ }^{1}$ European statistics estimate the annual need for percutaneous coronary interventions at 739 per million inhabitants and coronary artery bypass grafting at 436 per million inhabitants. ${ }^{2}$ Approximately $60 \%$ of these patients have multivessel disease and potentially could be treated with either bypass surgery or balloon angioplasty. ${ }^{3}$ Despite the publication of a number of trials comparing bypass surgery with angioplasty, ${ }^{4}$ the most appropriate treatment is still a matter of debate. 
These trials suggest that the results are similar in terms of survival and myocardial infarctions but that patients who undergo bypass surgery require fewer reinterventions.

The major concerns of surgeons are incompleteness of revascularization and the high rate of repeat interventions with angioplasty. When interpreting the results from these earlier trials, however, it is important to realize that improvements in both surgical and percutaneous techniques have occurred, calling into question the current validity of these earlier conclusions. Thus although surgery may still be seen as the most appropriate technique for multivessel disease when compared with conventional balloon angioplasty, this may not be true when stent placement-the current standard of practice ${ }^{5,6}$ - is added to the angioplasty procedure.

The specific aim of this study was to evaluate the clinical outcomes of patients with multivessel coronary artery disease treated with stented angioplasty versus conventional bypass surgery in a large, well-controlled, multicenter, multinational study. This report focuses in detail on outcomes of the surgical cohort. There is also an overall comparison of the outcomes in the surgical and stent groups at 2 years and an analyis of the differences in the pattern of response in patients with diabetes.

\section{Methods \\ Study Design}

The Arterial Revascularization Therapies Study (ARTS) was a randomized trial that required a consensus of the surgeon and the interventional cardiologist regarding equivalent treatability of the patient by either technique. Informed consent was obtained from each patient and the institutional review board approved the protocol. A detailed description of the protocol has been reported elsewhere. 7

\section{Selection of Patients}

Patients with angina or ischemia but no previous bypass surgery or angioplasty were selected after agreement between surgeons and cardiologists, randomly assigned after written informed consent through a central telephone service, and treated with either surgery or stented angioplasty. Sixty percent of patients in the surgical arm and $57 \%$ in the stent arm had stable angina (Canadian Cardiovascular Society class 1, 2, 3, or 4). ${ }^{8}$ Unstable angina pectoris (Braunwald class IB, IC, IIB, IIC, IIIB, or IIIC) ${ }^{9}$ was present in $35 \%$ of the surgical group versus $37 \%$ of the stent group, and silent ischemia was present in 5\% of the surgical group and $6 \%$ of the stent group (Table 1). Patients were eligible for coronary revascularization if they had at least two de novo lesions (located in different vessels and in different territories) potentially amenable to bypass surgery or stent implantation. Patients with left main stem stenosis were excluded.

Concomitant risk factor modification was an important aspect of treatment for all patients in the ARTS trial. Smokers were counseled and assisted with smoking cessation. Patients with hypertension were required to have their blood pressure lowered to less than 140/90 $\mathrm{mm} \mathrm{Hg}$. Patients with diabetes were required to be treated with diet, exercise, oral agents, and insulin as clinically indicated. Pharmacologic treatment was instituted for patients with total cholesterol level greater than $5.5 \mathrm{mmol} / \mathrm{L}$, according to the most recent European guidelines. ${ }^{10}$

Exclusion criteria included a left ventricular ejection fraction less than $30 \%$, overt congestive heart failure, a history of previous cerebrovascular accident, transmural myocardial infarction within the previous week, severe hepatic or renal disease, diseased saphenous veins, and the need for concomitant major surgery (eg, valve surgery or resection of aortic or left ventricular aneurysm, carotid endarterectomy, abdominal aortic aneurysm surgery). Finally, patients with intolerance or contraindication to aspirin or ticlopidine and those with neutropenia or thrombocytopenia were also excluded.

\section{General Management Considerations and Operator Certification}

Surgery and cardiac interventions were performed at 67 sites. The institutions involved in the ARTS trial had to perform at least 400 coronary bypass procedures per year in which the thoracic artery was used in $80 \%$ of the cases. ${ }^{11}$ The standard procedure for coronary bypass entailed extracorporeal circulation and cardiac arrest. The internal thoracic artery had to be used for revascularization of the left anterior descending coronary artery or the diagonal branches during extracorporeal circulation. The use of other arterial conduit material was discouraged. The remaining vessels could be bypassed by use of the greater saphenous vein in whatever configuration the surgeon deemed appropriate. Anesthetic techniques and the type of cardioplegic solution were not standardized.

A minimum of 500 angioplasty cases per center and a minimum of 100 procedures per year per operator were required for sites to qualify as participants in the ARTS trial. Angiographic criteria for inclusion in the trial have been previously been published elsewhere. ${ }^{7}$

\section{End Points}

The objective of this study was to compare bypass surgery with stented angioplasty with the Cordis Palmaz-Schatz Crown or CrossFlex stent (Cordis Corporation, Miami Lakes, Fla) in patients with multivessel coronary disease. The primary end point was defined as the absence of any of the following major adverse cardiac and cerebrovascular events within 12 months after random assignment: death, cerebrovascular event, documented nonfatal myocardial infarction, or repeated revascularization by percutaneous intervention or bypass surgery. ${ }^{7,12}$ In the primary comparison of the two treatment strategies, all deaths (cardiac and noncardiac causes) were reported. Cerebrovascular events were classified into three major categories: stroke, transient ischemic attack, and reversible ischemic neurologic deficit.

After random assignment, all myocardial infarctions were counted as events, whether they occurred spontaneously or in association with coronary artery bypass grafting surgery or angioplasty procedures. Myocardial infarctions were confirmed only after the relevant electrocardiograms were analyzed by the electrocardiographic core laboratory and adjudicated by the clinical events committee. Every subsequent revascularization procedure was recorded, including the reasons for the procedure. 
TABLE 1. Baseline characteristics of the patients included in the intent-to-treat-analysis

\begin{tabular}{|c|c|c|}
\hline & $\begin{array}{c}\text { Stented } \\
\text { angioplasty } \\
(n=600)\end{array}$ & $\begin{array}{l}\text { Coronary artery } \\
\text { bypass grafting } \\
\quad(n=605)\end{array}$ \\
\hline Male sex & $77 \%$ & $76 \%$ \\
\hline Age $(y$, mean $\pm S D)$ & $61 \pm 10(30-83)$ & $61 \pm 9(32-82)$ \\
\hline Body mass index $\left(\mathrm{kg} / \mathrm{m}^{2}\right.$, mean $\left.\pm \mathrm{SD}\right)$ & $27.2 \pm 3.7$ & $27.4 \pm 3.7$ \\
\hline \multicolumn{3}{|l|}{ Previous conditions } \\
\hline Myocardial infarction ( 0 -wave and non- 0 -wave) & $44 \%$ & $42 \%$ \\
\hline Diabetes mellitus & $19 \%$ & $16 \%$ \\
\hline Hypertension & $45 \%$ & $45 \%$ \\
\hline Hypercholesterolemia & $58 \%$ & $58 \%$ \\
\hline Family history & $39 \%$ & $42 \%$ \\
\hline Peripheral vascular disease & $6 \%$ & $5 \%$ \\
\hline Chronic obstructive pulmonary disease & $5 \%$ & $5 \%$ \\
\hline Current smoker & $28 \%$ & $26 \%$ \\
\hline Stable angina* & $57 \%$ & $60 \%$ \\
\hline Unstable anginat & $37 \%$ & $35 \%$ \\
\hline Silent ischemia & $6 \%$ & $5 \%$ \\
\hline Ejection fraction (\%) & $61 \% \pm 12 \%$ & $60 \% \pm 13 \%$ \\
\hline Segments DS $>50 \%$ & $2.83 \pm 1.02$ & $2.80 \pm 1.04$ \\
\hline \multicolumn{3}{|l|}{ No. of vessels diseased } \\
\hline One & $1.5 \%$ & $0.3 \%$ \\
\hline Two & $68.1 \%$ & $66.6 \%$ \\
\hline Three & $30.4 \%$ & $33.1 \%$ \\
\hline \multicolumn{3}{|l|}{ Vessel territory $\ddagger$} \\
\hline Right coronary artery & $71.2 \%$ & $72.4 \%$ \\
\hline Left anterior descending artery & $89.9 \%$ & $90.5 \%$ \\
\hline Left circumflex artery & $71.2 \%$ & $72.4 \%$ \\
\hline Left main stem artery§ & $0.2 \%$ & $0.2 \%$ \\
\hline Bifurcation or side branch involvedł & $34 \%$ & $31 \%$ \\
\hline Total occlusion $\ddagger$ & $3 \%$ & $5 \%$ \\
\hline
\end{tabular}

*According to the classification system of the Canadian Cardiovascular Society.

†According to reference 16 .

$\ddagger$ Assessed by an independent angiographic core laboratory.

§Protocol violation.

Secondary objectives of the study were to compare both strategies at 2 years with respect to the following: anginal status; medication use; the combined end point of death, myocardial infarction and stroke; and the itemized outcomes of death, myocardial infarction, stroke, or revascularization procedure. Events were counted from the time of random assignment, whereas the clinical status was assessed at predetermined times of 1 month, 6 months, 12 months, and 24 months after the procedure.

One patient was unavailable for follow up, 3 were alive but had withdrawn their consent from further participation in the trial, and 2 patients were never treated with either modality.

\section{Statistical Analysis}

The required sample size $(2 \times 600$ patients $)$ was based on rejection of the null hypothesis that at 1 year the frequency of major adverse cardiac and cerebrovascular events in favor of bypass surgery (event-free survival) would not exceed $7 \%$. The actual sample size achieved a power of $92 \%$ with the assumption of a 2 -sided type I error level $(\alpha)$ of .05 .

Continuous variables were expressed as mean \pm SD and compared with the unpaired Student $t$ test. The Fisher exact test was used for categoric variables. Wilcoxon scores were used for cate- goric variables with an ordinal scale. Discrete variables were expressed as counts and percentages and were compared in terms of relative risks (for surgery vs stenting) with $95 \%$ confidence intervals calculated by the formula of Greenland and Robins. ${ }^{13}$ All statistical tests were 2-tailed. Event-free survivals were estimated according to the Kaplan-Meier method, and differences were assessed with the log-rank test.

\section{Results}

\section{Patient Characteristics and Study Flow Chart}

Between April 1997 and June 1998, a total of 1205 patients were randomly assigned to undergo coronary artery bypass grafting surgery (605 patients) or angioplasty with stent implantation (600 patients) at 67 participating centers. Table 1 shows their baseline demographic and angiographic characteristics. As indicated in Table 2, 5 patients (1 assigned to undergo stented angioplasty and 4 assigned to undergo surgery) did not undergo coronary revascularization and instead continuted to receive pharmacologic treatment. The average time elapsed between random assign- 


\section{TABLE 2. Study flow chart}

\begin{tabular}{|c|c|c|}
\hline & $\begin{array}{c}\text { Stented } \\
\text { angioplasty } \\
(\mathrm{n}=600)\end{array}$ & $\begin{array}{c}\text { Coronary artery } \\
\text { bypass grafting } \\
(\mathrm{n}=605)\end{array}$ \\
\hline Patients randomly assigned & 600 & 605 \\
\hline Treated according to random assignment & $593(98.8 \%)$ & $579(95.9 \%)$ \\
\hline Medical treatment only & 1 & 4 \\
\hline Time on waiting list $(d$, mean $\pm S D)$ & $11 \pm 16$ & $27 \pm 39$ \\
\hline Deaths on waiting list & 0 & 3 \\
\hline Cross-over from stent to coronary artery bypass grafting* & 6 & - \\
\hline \multirow[t]{2}{*}{ Cross-over from coronary artery bypass grafting to stent $\dagger$} & - & 19 \\
\hline & $(0-173)$ & $(0-362)$ \\
\hline Unavailable for follow-up at 2 years $\ddagger$ & 2 & 4 \\
\hline
\end{tabular}

*Three patients withdrew consent, 2 patients had significant left main disease, and in 1 case inappropriate patient selection occurred. tEight patients withdrew consent, in 8 cases the inclusion criteria were not met, in 1 case there was a miscommunication between the investigator and the study coordinator about the random assignment, 1 patient had a 0 -wave myocardial infarction while on the waiting list, and 1 patient had unstable angina develop while on the waiting list and was treated with stented angioplasty.

$\ddagger$ One patient was unavailable for follow-up, 3 were alive but had withdrawn their consent from further participation in the trial, and 2 patients were never treated with either modality.

ment and treatment was $27 \pm 39$ days (range 0-362 days) for the surgical group and $11 \pm 16$ days (range 0-173 days) for the stent group. Three patients assigned to undergo surgery died while on the waiting list. Six patients allocated to the stent arm crossed over to the surgical treatment arm, whereas 19 patients assigned to surgery were treated with stent implantation. During the initial hospital stay, 14 patients initially assigned to undergo stenting underwent surgical revascularization, 3 urgently and 11 electively, after a complicated or unsatisfactory percutaneous treatment. Similarly, 2 patients who had undergone surgery had further angioplasty during the same hospital stay. Thus 579 patients in the surgical group (95.9\%) and 593 patients in the stent group $(98.8 \%)$ were treated according to the assigned treatment.

\section{Assessment of Revascularization (Figure 1)}

There were 579 patients actually operated on; $2.8 \pm 1.1$ lesions per patient were present, and $2.7 \pm 1.1$ distal anastomoses were performed with $2.5 \pm 0.7$ conduits. At least one arterial conduit was used in $93 \%$ of the cases, and the left anterior descending artery was revascularized with an arterial conduit in $95 \% ; 1.8 \%$ of the patients received a single bypass, $51.6 \%$ received a double bypass, $33.6 \%$ received a triple bypass, $6.9 \%$ received a quadruple bypass, and $0.5 \%$ received a quintuple bypass. The mean operative time for surgery was $248 \pm 76$ minutes, the mean bypass time was $75 \pm 35$ minutes, and the mean crossclamp time was $45 \pm 27$ minutes. Cardiac arrest was achieved with crystalloid cardioplegia in 325 cases and blood cardioplegia in 191. In the remainder, a combination of techniques was used with additional crossclamping and topical hypothermia in 284 patients. To manage cardiac failure after the operation, prolonged extracorporeal circulation was necessary in
$1 \%$ of the cases and intra-aortic balloon pumping was necessary in $2.4 \%$. A left ventricular assist device was necessary in $1 \%$.

In the first 24 hours after intervention, abnormal creatine kinase MB levels were observed in $61 \%$ of the surgical group and $31 \%$ of the stent group. Eight patients died in the hospital between 1 and 18 days after the operation. The causes of death were excessive bleeding (1 patient), ventricular fibrillation $(\mathrm{n}=2)$, mesenteric infarction $(\mathrm{n}=2)$, cardiogenic shock $(\mathrm{n}=2)$, and myocardial infarction $(\mathrm{n}=$ 1). The overall operative mortality was $1.3 \%$. By comparison, the in-hospital mortality rate in the stented angioplasty group was $1 \%(n=6)$. A total of 571 patients were weaned off the bypass machine, extubated, and discharged from hospital. The lengths of stay were $11.3 \pm 9.1$ days in the surgical group and $3.4 \pm 4.8$ days in the stent group.

\section{Outcomes at 30 Days after Random Assignment}

At 30 days after random assignment there were a total of 11 deaths, including the 3 deaths of patients on the waiting list. A further 6 patients had a cerebrovascular event (1.0\%), and 18 had a myocardial infarction (3.0\%). Reintervention was necessary in 1 case $(0.2 \%)$ by means of bypass surgery and in 1 case $(0.2 \%)$ by additional angioplasty. The events in the stented angioplasty group were similar: 9 patients died (1.5\%, including the 6 in-hospital deaths), 4 patients $(0.7 \%)$ had a cerebrovascular accident, and 19 patients (3.0\%) had a myocardial infarction.

\section{Outcomes at 1 Year}

The outcomes at 1 year have previously been discussed in detail elsewhere. ${ }^{12}$ The primary end-point criterion was met by 157 of 600 patients (26.2\%) assigned to undergo stented angioplasty and 74 of 605 patients (12.2\%) assigned to 


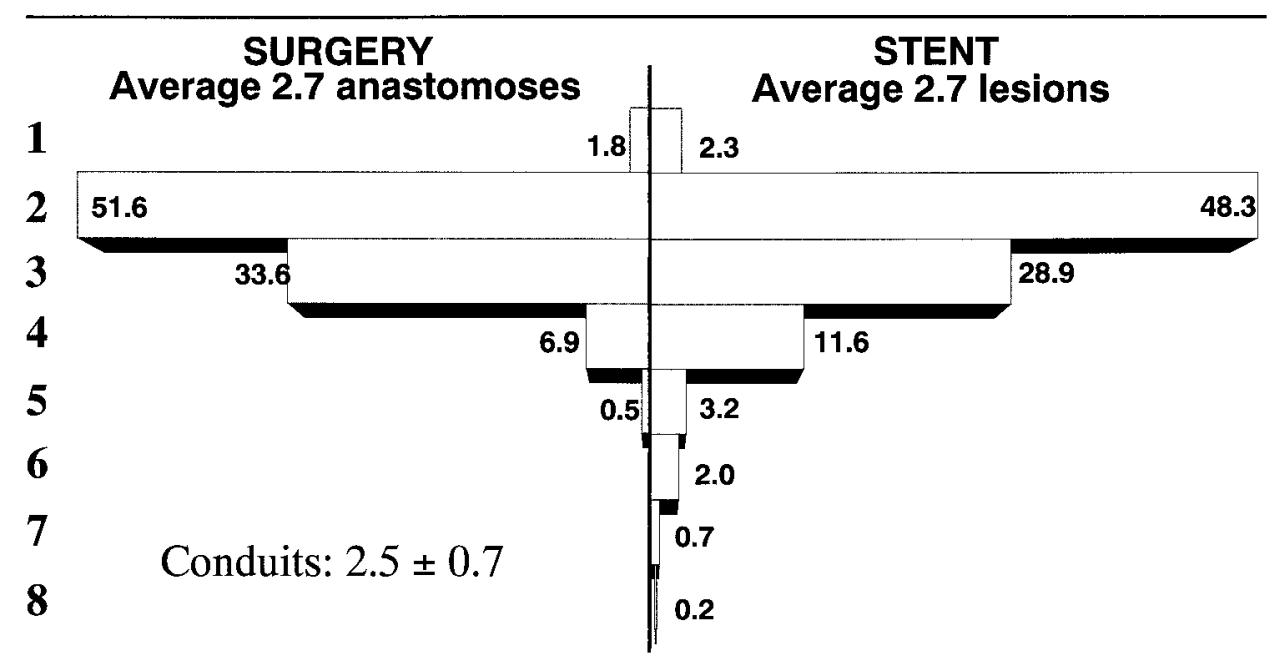

Figure 1. Percentages of vessels revascularized in surgical and stented angioplasty cohorts.

undergo bypass surgery (relative risk 2.14; $95 \%$ confidence interval 1.66-2.75). There was no significant difference in freedoms from death, stroke, or myocardial infarction between the stent and surgical groups $(90.7 \%$ vs $91.2 \%$, respectively, relative risk $1.07,95 \%$ confidence interval 0.75 1.52). Of the remaining patients, however, $16.8 \%$ in the stent group and $3.5 \%$ in the surgical group underwent repeated revascularization, an absolute difference of $13.3 \%$.

\section{Outcomes at 2 Years}

Events per patient and ranking of clinical events at 2-year follow-up are shown in Table 3. The primary clinical end point (major adverse cardiac and cerebrovascular events) was reached by $92(15.2 \%)$ of the 605 patients assigned to undergo bypass surgery, compared with $183(30.5 \%)$ of the 600 patients assigned to undergo stented angioplasty (relative risk $0.39,95 \%$ confidence interval $0.29-0.53$ ). Freedoms from death, stroke, and myocardial infarction were similar in the surgical and the stented angioplasty groups $(89.6 \%$ vs $89.2 \%$, respectively, relative risk $0.92,95 \%$ confidence interval $0.62-1.35$ ). The difference in clinical outcomes between the study groups at 2 years was almost entirely due to the need for more repeated revascularizations in the stent group.

Among patients free from death, stroke, and myocardial infarction, the need for additional revascularization was $14.9 \%$ higher after percutaneous treatment than after surgery. This difference in clinical outcome for both treated groups is reflected in the Kaplan-Meier estimates of eventfree survival and freedom from death, stroke, and myocardial infarction (Figure 2). The improved 2-year outcome in the surgical group is also partly reflected in the differences in anginal status and antianginal medication use between the two groups (Table 4). At 2-year follow-up, $87.2 \%$ of the surgical group were symptom free, compared with $79.7 \%$ of the stent group $(P=.001)$.

\section{Diabetes}

A total of 208 patients in this study (17.3\%) had diabetes (3.2\% with type 1 ; Table 3 ). The primary clinical end point had been reached at 2 years by 17 of the 96 patients with diabetes assigned to undergo bypass surgery $(17.7 \%)$, versus 49 of the 112 assigned to undergo stented angioplasty (43.8\%, relative risk 2.47 ; 95\% confidence interval 1.53 3.99). The incidences of death, stroke, and myocardial infarction were similar (14.6\% in the surgical group vs $16.1 \%$ in the stent group, relative risk $1.10,95 \%$ confidence interval 0.58-2.10). However, the reintervention rate was markedly lower among the patients with diabetes who were treated with surgery than among those who were treated with stented angioplasty (5.2\% vs $35.7 \%$, relative risk 6.86 , 95\% confidence interval 2.82-16.68). This absolute difference in the need for reintervention of $30.5 \%$ was also markedly higher than the difference of $19.1 \%$ observed for the total group and the absolute difference of $13.2 \%$ for the patients without diabetes.

\section{Discussion}

Coronary artery bypass surgery is a well-established and well-documented technique. However, angioplasty with stent implantation has had a significant impact on the referrals of patients for surgery during the past few years. Although the role of angioplasty in patients with single-vessel disease is well established, it has generally been assumed that bypass surgery is the procedure of choice for patients with multivessel disease. Arguments for angioplasty have included that it is less invasive and that there are long waiting lists for surgery. Surgeons have countered with 
TABLE 3. Frequencies of primary clinical end points at 2 years (730 days) in descending order of severity and total number of events

\begin{tabular}{|c|c|c|c|c|c|c|}
\hline & \multicolumn{2}{|c|}{ RANKING* } & \multicolumn{2}{|c|}{ Patients with events $\dagger$} & \multirow[b]{2}{*}{$\begin{array}{c}\text { Relative } \\
\text { risk }\end{array}$} & \multirow[b]{2}{*}{$\begin{array}{l}95 \% \text { confidence } \\
\text { interval }\end{array}$} \\
\hline & $\begin{array}{c}\text { Stented } \\
\text { angioplasty }\end{array}$ & $\begin{array}{l}\text { Coronary artery } \\
\text { bypass grafting }\end{array}$ & $\begin{array}{c}\text { Stented } \\
\text { angioplasty }\end{array}$ & $\begin{array}{l}\text { Coronary artery } \\
\text { bypass grafting }\end{array}$ & & \\
\hline All patients & 600 & 605 & 600 & 605 & & \\
\hline Patients with diabetes & 112 & 96 & 112 & 96 & & \\
\hline \multicolumn{7}{|l|}{ Death } \\
\hline All patients & $16(2.8 \%)$ & $22(3.6 \%)$ & $17(2.8 \%)$ & $22(3.6 \%)$ & 0.78 & $0.42-1.45$ \\
\hline Patients with diabetes & $8(7.1 \%)$ & $3(3.1 \%)$ & $8(7.1 \%) \times$ & $3(3.1 \%)$ & 2.29 & $0.62-8.38$ \\
\hline \multicolumn{7}{|l|}{ CVAł } \\
\hline All patients & $14(2.3 \%)$ & $16(2.6 \%)$ & $16(1.7 \%)$ & $13(2.1 \%)$ & 0.95 & $0.48-1.86$ \\
\hline Patients with diabetes & $3(2.7 \%)$ & $6(6.3 \%)$ & $4(3.6 \%)$ & $6(6.3 \%)$ & 0.57 & $0.17-1.97$ \\
\hline \multicolumn{7}{|l|}{ Myocardial infarction } \\
\hline All patients & $34(5.7 \%)$ & $25(4.1 \%)$ & $40(6.7 \%)$ & $31(5.1 \%)$ & 1.30 & $0.83-2.05$ \\
\hline Patients with diabetes & $7(6.3 \%)$ & $5(5.2 \%)$ & $10(8.9 \%)$ & $7(7.3 \%)$ & 1.22 & $0.49-3.09$ \\
\hline \multicolumn{7}{|c|}{0 -wave myocardial infarction } \\
\hline All patients & $28(4.7 \%)$ & $21(3.5 \%)$ & $33(5.5 \%)$ & $26(4.3 \%)$ & 1.28 & $0.78-2.11$ \\
\hline Patients with diabetes & $6(5.4 \%)$ & $2(2.1 \%)$ & $8(7.1 \%)$ & $4(4.2 \%)$ & 1.71 & $0.53-5.52$ \\
\hline \multicolumn{7}{|c|}{ Non-0-wave myocardial infarction } \\
\hline All patients & $6(1.0 \%)$ & $4(0.7 \%)$ & $7(1.2 \%)$ & $5(0.8 \%)$ & 1.41 & $0.45-4.42$ \\
\hline Patients with diabetes & $1(0.9 \%)$ & $3(3.1 \%)$ & $2(1.8 \%)$ & $3(3.1 \%)$ & 0.57 & $0.10-3.35$ \\
\hline \multicolumn{7}{|l|}{ Reintervention } \\
\hline All patients & $118(19.7 \%)$ & $29(4.8 \%)$ & $147(24.5 \%)$ & $33(5.5 \%)$ & 4.49 & $3.13-6.44$ \\
\hline Patients with diabetes & $31(27.7 \%)$ & $3(3.1 \%)$ & $40(35.7 \%)$ & $5(5.2 \%)$ & 6.86 & $2.82-16.68$ \\
\hline \multicolumn{7}{|c|}{ Reoperative coronary artery bypass grafting } \\
\hline All patients & $40(6.7 \%)$ & $5(0.8 \%)$ & $53(8.8 \%)$ & $7(1.2 \%)$ & 7.64 & $3.50-16.66$ \\
\hline Patients with diabetes & $11(9.8 \%)$ & $0(0.0 \%)$ & $14(12.5 \%)$ & $2(2.1 \%)$ & 6.00 & $1.40-25.74$ \\
\hline \multicolumn{7}{|c|}{ Reinterventional percutaneous transluminal coronary angioplasty } \\
\hline All patients & $78(13.0 \%)$ & $24(4.0 \%)$ & $107(17.8 \%)$ & $30(5.0 \%)$ & 3.60 & $2.44-5.31$ \\
\hline Patients with diabetes & $20(17.9 \%)$ & $3(3.1 \%)$ & $28(25.0 \%)$ & $4(4.2 \%)$ & 6.00 & $2.18-16.50$ \\
\hline \multicolumn{7}{|l|}{ Event free§ } \\
\hline All patients & $417(69.5 \%)$ & $513(84.8 \%)$ & & & & \\
\hline Patients with diabetes & $63(56.3 \%)$ & $79(82.3 \%)$ & & & & \\
\hline \multicolumn{7}{|l|}{ Any event } \\
\hline All patients & & & $183(30.5 \%)$ & $92(15.2 \%)$ & 2.01 & $1.60-2.51$ \\
\hline Patients with diabetes & & & $49(43.8 \%)$ & $17(17.7 \%)$ & 2.47 & $1.53-3.99$ \\
\hline
\end{tabular}

In the stented angioplasty arm 1 patient had a myocardial infarction while on the waiting list, whereas in the coronary artery bypass grafting arm 3 patients died while on the waiting list, 1 patient had a cerebrovascular accident, and 4 patients had myocardial infarctions.

*Frequency of primary clinical end points in descending order of severity.

tIf a patient required repeat angioplasty and later coronary artery bypass grafting, the total count at 365 days would reflect both events, not just the first that occurred.

fln the stent group 5 cases were thrombotic, 1 was hemorrhagic, and others were unknown. In the surgical group 7 were thrombotic, 1 was hemorrhagic, and others were unknown.

§Wilcoxon rank-sum test $(P=.0001)$.

concerns that angioplasty may provide incomplete revascularization and have responded by creating off-pump and minimally invasive surgical techniques. The surgical community has watched the advances in stented angioplasty with great interest, because they have had a significant impact on referrals for surgery, with a resulting dramatic reduction or even elimination of surgical waiting lists. Surgeons naturally wonder whether this trend toward stented angioplasty rather than surgery is justified by the available scientific evidence.

The ARTS trial allows a direct comparison of two entirely different approaches to coronary revascularization in patients with multivessel coronary artery disease. This trial showed no significant difference in the frequency of death, stroke, and myocardial infarction between surgery and stented angioplasty. It is important to emphasize that in the early postoperative period the mortalities in the two arms were very similar $(0.7 \%$ vs $1 \%) .{ }^{12}$ The most significant difference in favor of surgery was related to the need for repeated revascularization at 24 months (14.9\% difference). Compared with previous trials with balloon angioplasty alone in a similar population, ${ }^{5}$ the need for urgent surgical revascularization after failed or complicated balloon angioplasty had fallen from $4.6 \% \%^{5}$ to $0.5 \%$. As noted previously, 


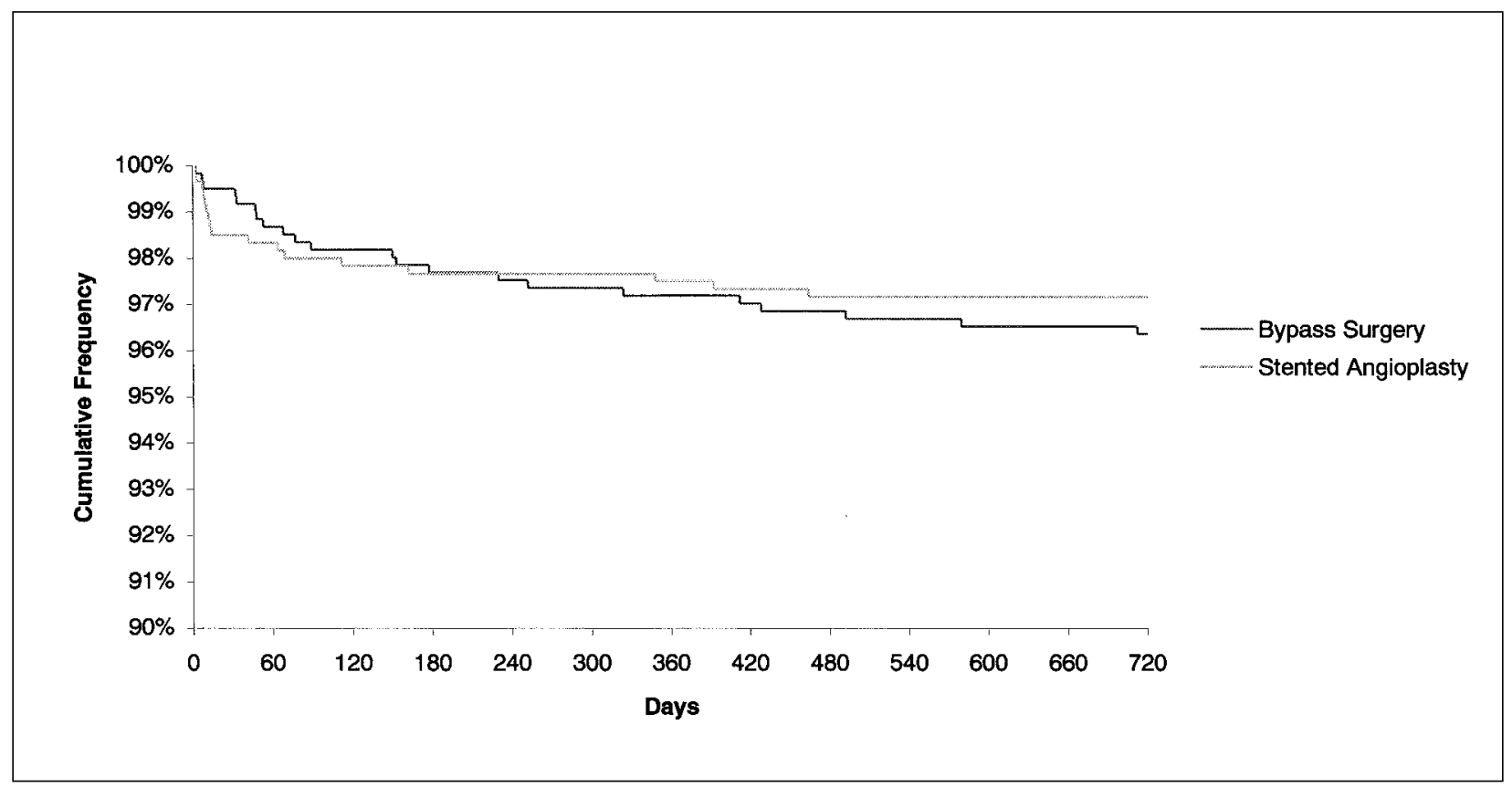

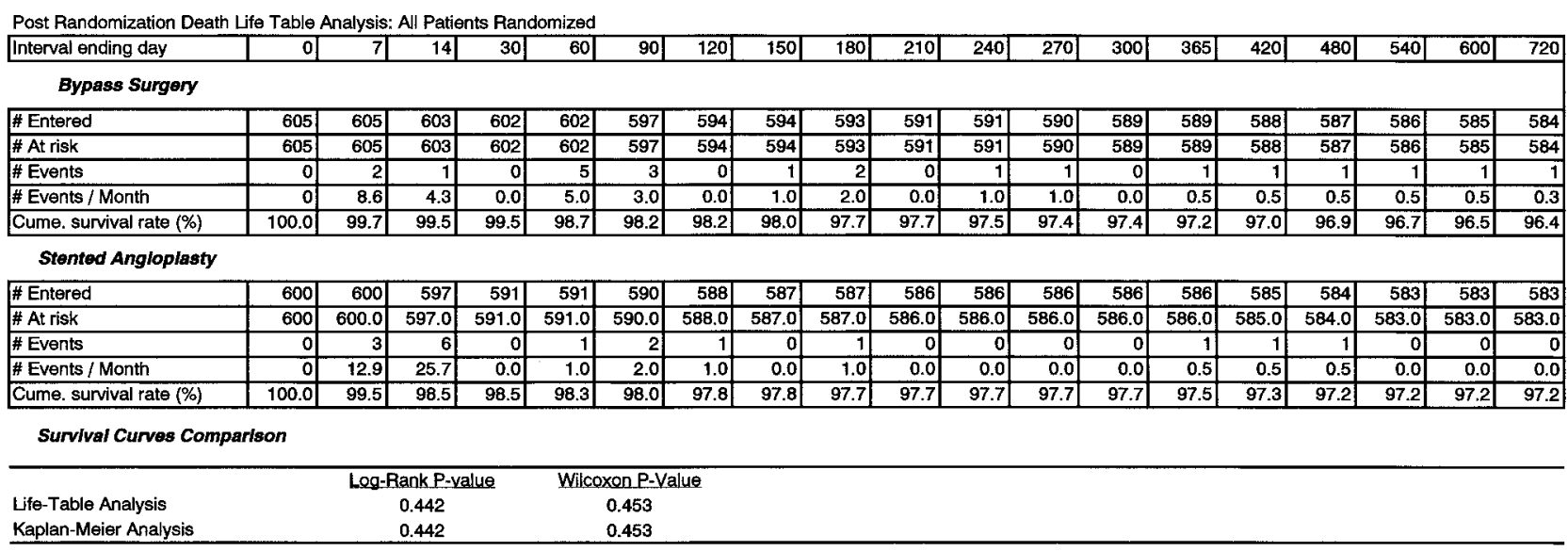

Figure 2. Two-year event-free survival curves of patients enrolled in ARTS trial and assigned to undergo stenting (broken line) versus bypass surgery (solid line). A, Actuarial survival for stent group versus surgical group $(P=$ .75).

the difference in clinical outcome at 1 year between the surgical and percutaneous approach has been reduced by approximately $50 \%$ relative to other studies. ${ }^{5}$ This considerable improvement in the percutaneous approach is due largely to the increased safety and partial prevention of restenosis provided by the stent.

In the ARTS trial the degree of revascularization achieved in the group treated with multivessel stenting is now comparable to that in the surgical cohort. In this trial 2.7 out of 2.8 stenotic lesions detected on the diagnostic angiogram were successfully treated with stented angioplasty, whereas in the Coronary Angioplasty versus Bypass
Revascularisation Investigation trial ${ }^{14}$ only 2.1 out of 3.4 stenotic lesions were successfully treated, and in the Bypass Angioplasty Revascularization Investigation trial ${ }^{15}$ only 1.9 out of 3.5 stenotic lesions were successfully treated. The adequacy of revascularization with surgical techniques in this study in the surgical cohort was very similar: 2.7 out of 2.8 lesions detected were treated with bypass grafts. The aim of surgery is always to achieve complete revascularization.

The ARTS trial was designed in April 1996 and initiated in April 1997; patient recruitment was completed in June 1998. During this period the time that elapsed between 


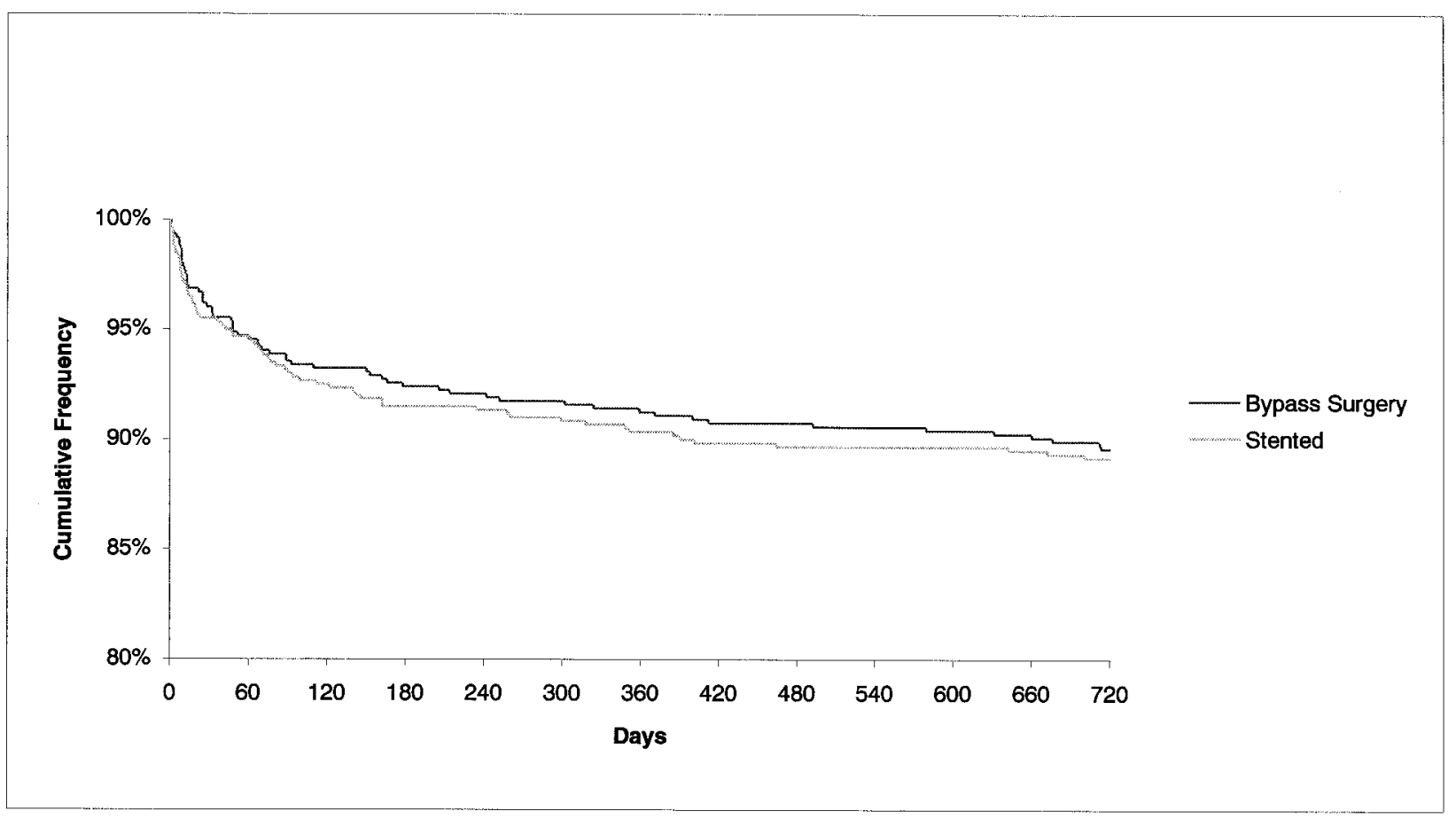

Post Randomization Death, Stroke or Ml: Life Table Analysis: All Patients Randomized

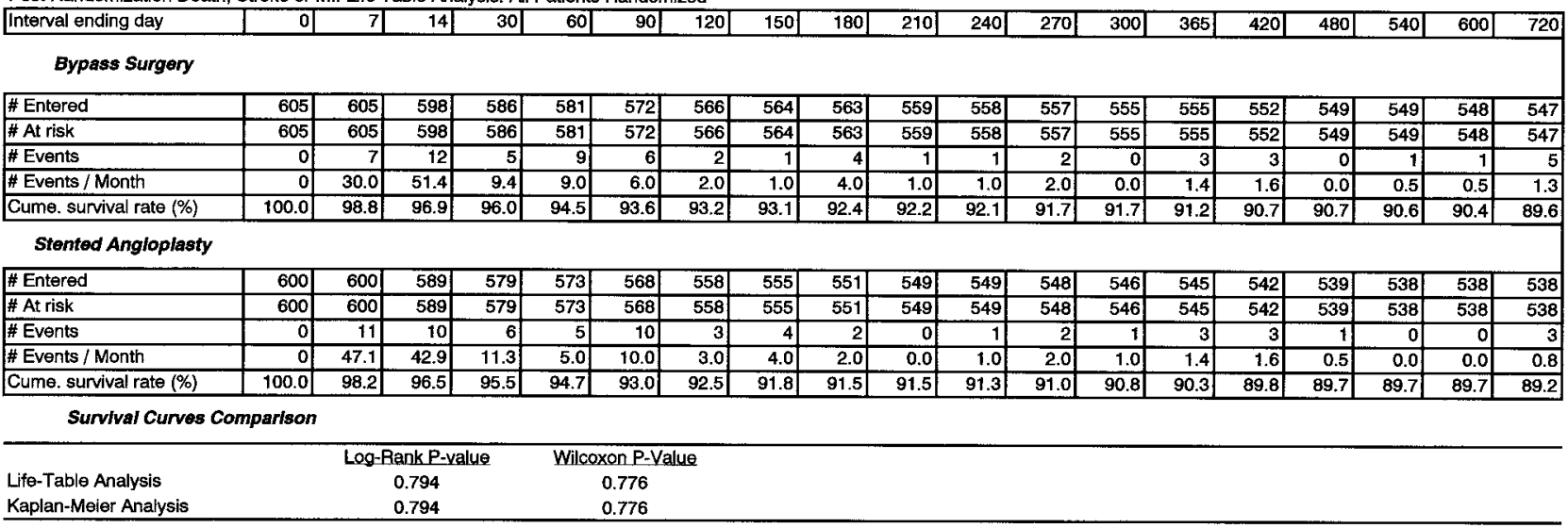

Figure 2. Cont'd. B, Kaplan-Meier event-free survival curves for death, myocardial infarction, or cerebrovascular events for stent group versus surgical group $(P=.71)$.

random assignment and treatment was approximately three times as long for the surgical cohort as for the stent cohort. Eight major adverse cardiac events occurred in the surgical group during the waiting period, versus 1 in the stent group. There are reports that the waiting list for cardiac surgery is in itself a considerable risk factor for these patients. ${ }^{16-18}$ Since 1997, the waiting-time for surgery has been markedly reduced or even eliminated in many countries. It is also worth noting that the in-hospital stay was more than three times as long for patients undergoing surgery as for those undergoing stented angioplasty. This difference has probably not changed substantially.

In the selection of centers for the trial, it was surprising that many centers could not be included because they did not routinely use the internal thoracic artery, not to mention an all-arterial approach. The use of an internal thoracic graft to the left anterior descending and saphenous vein grafts to the remaining vessels that require treatment still appears to be the standard of care, at least in Europe. ${ }^{19}$ Adoption of this standard was necessary to ensure a basically similar approach to surgery in all 67 centers.

\section{Evolving Technology}

There have been new developments in coronary revascularization, such as off-pump surgery, minimally invasive approaches, and new techniques in anesthesiology. ${ }^{20-23} \mathrm{Al}-$ 


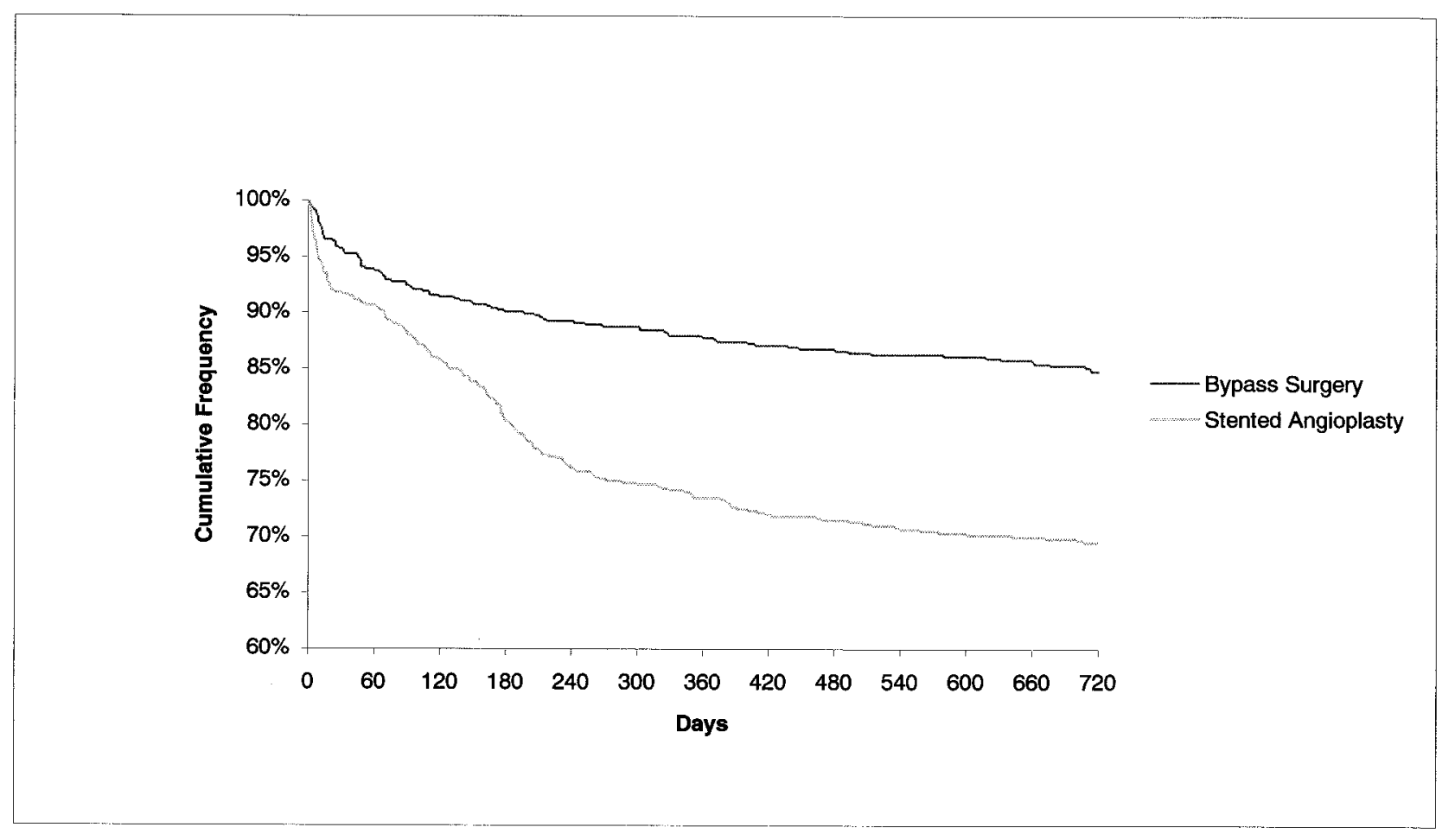

Post-device Target Lesion RPTCA and CABG Life Table Analysis: All Patients Treated

\begin{tabular}{|c|c|c|c|c|c|c|c|c|c|c|c|c|c|c|c|c|c|c|c|}
\hline Interval ending day & 0 & 7 & 14 & 30 & 60 & 90 & 120 & 150 & 180 & 210 & 240 & 270 & \begin{tabular}{l|l}
300 \\
\end{tabular} & 365 & 420 & 480 & 540 & 600 & 720 \\
\hline \multicolumn{20}{|l|}{ Bypass Surgery } \\
\hline \# Entered & 605 & 605 & 598 & 584 & 579 & 567 & 559 & 553 & 549 & 545 & 543 & 540 & 537 & 537 & 531 & 527 & 524 & 522 & 521 \\
\hline \# At risk & 605 & 605.0 & 598.0 & 584.0 & 579.0 & 567.0 & 559.0 & 553.0 & 549.0 & 545.0 & 543.0 & 540.0 & 537.0 & 537.0 & 531.0 & 527.0 & 524.0 & 522.0 & 521.0 \\
\hline \# Events & 0 & 7 & 14 & 5 & 12 & 8 & 6 & 4 & 4 & 2 & 3 & 3 & 0 & 6 & 4 & 3 & 2 & 1 & 8 \\
\hline \# Events / Month & 0 & 30.0 & 60.0 & 9.4 & 12.0 & 8.0 & 6.0 & 4.0 & 4.0 & 2.0 & 3.0 & 3.0 & 0.0 & 2.8 & 2.2 & 1.5 & 1.0 & 0.5 & 2.0 \\
\hline Cume. survival rate $(\%)$ & 100.0 & 98.8 & 96.5 & 95.7 & 93.7 & 92.4 & 91.4 & 90.7 & 90.1 & 89.8 & 89.3 & 88.8 & \begin{tabular}{l|l}
88.8 \\
\end{tabular} & 87.8 & 87.1 & 86.6 & 86.3 & \begin{tabular}{l|l}
86.1 \\
\end{tabular} & 84.8 \\
\hline \multicolumn{20}{|l|}{ Stentd Angloplasty } \\
\hline \# Entered & 600 & 600 & 575 & 561 & 551 & 544 & 528 & 514 & 503 & 482 & 466 & 457 & 451 & \begin{tabular}{l|l|}
448 \\
\end{tabular} & \begin{tabular}{l|l}
441 & \\
\end{tabular} & 432 & 429 & 424 & 422 \\
\hline \# At risk & 600 & 600.0 & 575.0 & 561.0 & 551.0 & 544.0 & 528.0 & 514.0 & 503.0 & 482.0 & 466.0 & 457.0 & 451.0 & 448.0 & 441.0 & 432.0 & 429.0 & 424.0 & 422.0 \\
\hline \# Events & 0 & 25 & 14 & 10 & 7 & 16 & 14 & 11 & 21 & 16 & 9 & 6 & 3 & 7 & 9 & 3 & 5 & 2 & 5 \\
\hline \# Events / Month & 0 & 107.1 & 60.0 & 18.8 & 7.0 & 16.0 & 14.0 & 11.0 & 21.0 & 16.0 & 9.0 & 6.0 & 3.0 & \begin{tabular}{l|l}
3.2 \\
\end{tabular} & \begin{tabular}{l|l}
4.9 \\
\end{tabular} & 1.5 & 2.5 & 1.0 & 1.3 \\
\hline Cume. survival rate (\%) & 100.0 & 95.8 & 93.5 & 91.8 & 90.7 & 88.0 & 85.7 & 83.8 & 80.3 & 77.7 & 76.2 & 75.2 & 74.7 & 73.5 & 72.0 & 71.5 & 70.7 & 70.3 & 69.5 \\
\hline
\end{tabular}

Survival Curves Comparison

\begin{tabular}{lcc}
\hline & Log-RankP-value & Wilcoxon P-Value \\
Life-Table Analysis & $<0.001$ & $<0.001$ \\
Kaplan-Meier Analysis & $<0.001$ & $<0.001$ \\
\hline
\end{tabular}

Figure 2. Cont'd. C, Kaplan-Meier event-free survival curves for death, cerebrovascular events, myocardial infarction, or any repeated revascularization stent group versus surgical group $(\boldsymbol{P}=.0001)$.

though these techniques may affect practice in the future, they did not represent standard practice except at a few centers of excellence. ${ }^{11,24-25}$ Thus the surgical data in this trial reflected the standardized approach to bypass surgery in 67 centers in 25 countries, not the standard of total arterial arterialization that might potentially be achieved in some centers of excellence.

However, the same caveats apply to the patients treated with stented angioplasty. Percutaneous stent procedures have also evolved substantially since 1997 . Direct stenting without balloon predilatation and intracoronary radiation therapy ${ }^{26,27}$ for in-stent restenosis are now part of the cardiologist's armamentarium. It is also worth noting that $40 \%$ of the 30-day events in the stent group were due to stent thrombosis, which occurred in $1.1 \%$ of the stented lesions but $3 \%$ of the patients. These events might have been prevented by the use of a glycoprotein receptor antagonist ${ }^{28}$ or heparin-coated stents. ${ }^{5}$ Finally, drug-eluting stents may 
TABLE 4. Anginal status, medication status, and health status of surviving patients

\begin{tabular}{|c|c|c|c|c|c|c|c|c|c|c|c|}
\hline & \multicolumn{2}{|c|}{ Baseline } & \multicolumn{2}{|c|}{$1 \mathrm{mo}$} & \multicolumn{3}{|c|}{$12 \mathrm{mo}$} & \multicolumn{3}{|c|}{$24 \mathrm{mo}$} & \multirow[b]{2}{*}{$\begin{array}{c}P \\
\text { value }\end{array}$} \\
\hline & $\begin{array}{c}\text { Stented } \\
\text { angioplasty }\end{array}$ & $\begin{array}{c}\text { Coronary } \\
\text { artery } \\
\text { bypass } \\
\text { grafting }\end{array}$ & $\begin{array}{c}\text { Stented } \\
\text { angioplasty }\end{array}$ & $\begin{array}{c}\text { Coronary } \\
\text { artery } \\
\text { bypass } \\
\text { grafting }\end{array}$ & $\begin{array}{c}P \\
\text { value }\end{array}$ & $\begin{array}{c}\text { Stented } \\
\text { angioplasty }\end{array}$ & $\begin{array}{c}\text { Coronary } \\
\text { artery } \\
\text { bypass } \\
\text { grafting }\end{array}$ & $\begin{array}{c}P \\
\text { value }\end{array}$ & $\begin{array}{c}\text { Stented } \\
\text { angioplasty }\end{array}$ & $\begin{array}{c}\text { Coronary } \\
\text { artery } \\
\text { bypass } \\
\text { grafting }\end{array}$ & \\
\hline Angina free & $0 \%$ & $0 \%$ & $87.2 \%$ & $95.5 \%$ & $<.001$ & $78.9 \%$ & $89.5 \%$ & $<.001$ & $79.7 \%$ & $87.2 \%$ & .001 \\
\hline Angina medication free & $7.5 \%$ & $4.6 \%$ & $16.4 \%$ & $29.4 \%$ & $<.001$ & $21.1 \%$ & $41.5 \%$ & $<.001$ & $22.9 \%$ & $39.6 \%$ & $<.001$ \\
\hline Angina and medication free & $0 \%$ & $0 \%$ & $14.9 \%$ & $28.6 \%$ & $<.001$ & $19.1 \%$ & $38.4 \%$ & $<.001$ & $20.2 \%$ & $35.0 \%$ & $<.001$ \\
\hline
\end{tabular}

markedly reduce restenosis and the need for repeated revascularization. ${ }^{29}$ These therapies, although promising, also cannot yet be considered "standard practice."

\section{Diabetes}

This study corroborates the findings of the Bypass Angioplasty Revascularization Investigation trial with respect to the adverse clinical impact of diabetes in patients undergoing percutaneous coronary interventions. On the basis of these data, it seems that bypass surgery is clearly the preferred approach for the treatment of patients with diabetes who have multivessel disease. For patients without diabetes the choice represents a series of trade-offs. There was no difference at 2 years in terms of death, myocardial infarction, or cerebrovascular accident between surgery and stented angioplasty. However, there was a substantially greater need for repeated interventions in the stent group, with the associated need for rehospitalization. On the other hand, surgery was associated with a longer initial hospital stay, a prolonged period of recovery, and greater costs. These trade-offs should be presented to the patient, and the best approach for each individual patient should be chosen after careful consideration of all the facts.

\section{Limitations of the Study}

Because of strict inclusion and exclusion criteria, patients treated in this study represent a small segment of patients treated by the study surgeons. Surgeons often operate on patients with more extensive disease than reported on in this study, and most randomized trials recruit eligible patients who represent only a small fraction of the population amenable to surgical revascularization. In this trial a prospective universe analysis showed that in any given week between $0 \%$ and $33 \%$ of patients with multivessel disease at the participating institution were actually enrolled in the ARTS trial. This wide range is attributable both to the restrictive eligibility criteria for the study and to local logistic considerations. In essence, these trials should be viewed as scientific experience testing concepts, expanding our knowledge of the field of revascularization and unraveling the need for improvement.
We thank Dr Brian Firth for his careful review of the manuscript and constructive comments.

\section{References}

1. Unger F. Worldwide survey on coronary interventions 1995. Report of the European Heart Academy of Sciences and ARTS. Cor Europaeum. 1999;7:128-46.

2. Unger F. Cardiac interventions in Europe 1997: coronary revascularization procedures and open heart surgery. Cor Europaeum. 1999;7: $177-86$.

3. Rigter H, Meijler AP, McDonnell J, Scholma JK, Bernstein SJ. Indications for coronary revascularisation: a Dutch perspective. Heart. 1997;77:211-8.

4. Pocock S J, Henderson RA, Rickards AF, et al. Meta-analysis of randomized trials comparing coronary angioplasty with bypass surgery. Lancet. 1995;346:1184-9.

5. Serruys PW, van Hout B, Bonnier H, Legrand V, Garcia E, Macaya C, et al. Randomized comparison of implantation of heparin-coated stents with balloon angioplasty in selected patients with coronary artery disease (Benestent II). Lancet. 1998;352:673-81.

6. Eeckhout E, Wijns W, Meier B, Goy JJ. Indications for intracoronary stent placement: the European view. Working Group on Coronary Circulation of the European Society of Cardiology. Eur Heart J. 1999;20:1014-9.

7. Serruys PW, Van Hout BA, Van den Brand MJ, et al. The ARTS (Arterial Revascularization Therapies Study): background, goals and methods. Int J Cardiovasc Interv. 1999;2:41-50.

8. Campeau L. Grading of angina pectoris. Circulation. 1976;54:522-3.

9. Braunwald E. Unstable angina. A classification. Circulation. 1989;80: 410-4.

10. Eagle KA, Guyton RA, Davidoff R, Ewy GA, Fonger J, Gardner TJ, et al. ACC/AHA ACC/AHA Guidelines for Coronary Artery Bypass Graft Surgery: A Report of the American College of Cardiology/ American Heart Association Task Force on Practice Guidelines (Committee to Revise the 1991 Guidelines for Coronary Artery Bypass Graft Surgery). American College of Cardiology/American Heart Association. J Am Coll Cardiol. 1999;34:1262-347.

11. Wood D. European and American recommendations for coronary heart disease prevention. Eur Heart J. 1998;19 Suppl A:A12-9.

12. Serruys PW, Unger F, Sousa JE, Jatene A, Bonner HJ, Schönberger JP, et al. Comparison of coronary-artery bypass surgery and stenting for the treatment of multivessel disease. N Engl J Med. 2001;344: $1117-24$.

13. Greenland S, Robins JM. Estimation of a common effect parameter from sparse follow-up data. Biometrics 1985;41:55-68.

14. First-year results of CABRI (Coronary Angioplasty versus Bypass Revascularisation Investigation). CABRI Trial Participants. Lancet. 1995;346:1179-84.

15. The Bypass Angioplasty Revascularization Investigation (BARI) Investigators. Comparison of coronary bypass surgery with angioplasty in patients with multivessel disease. $N$ Engl J Med. 1996;335:217-25. 
16. Bernstein SJ, Rigter H, Brorsson B, Hilborne LH, Leape LL, Meijler $\mathrm{AP}$, et al. Waiting for coronary revascularization: a comparison between New York State, The Netherlands and Sweden. Health Policy. 1997;42:15-27.

17. Teo KK, Spoor M, Pressey T, Williamson H, Calder P, Gelfand ET, et al. Impact of managed waiting for coronary artery bypass graft surgery on patients' perceived quality of life. Circulation. 1998;98(19 Suppl):II29-33.

18. Jackson NW, Doogue MP, Elliott JM. Priority points and cardiac events while waiting for coronary bypass surgery. Heart. 1999;81: 367-3.

19. Unger F, Frommer P, Hetzer R, et al. Standards and concepts in cardiac interventions: coronary artery disease-revascularization. Cor Europaeum. 1997;6:32-9.

20. Calafiore AM, Di Giammarco G, Teodori G, Gallina S, Maddestra N, Paloscia L, et al. Midterm results after minimally invasive coronary surgery (LAST operation). J Thorac Cardiovasc Surg. 1998;115:76371.

21. Benetti F, Mariani MA, Sani G, Boonstra PW, Grandjean JG, Giomarelli P, et al. Video-assisted minimally invasive coronary operations without cardiopulmonary bypass: a multicenter study. J Thorac Cardiovasc Surg. 1996;112:1478-84.

22. Gu YJ, Mariani MA, van Oeveren W, Grandjean JG, Boonstra PW. Reduction of the inflammatory response in patients undergoing minimally invasive coronary artery bypass grafting. Ann Thorac Surg. 1998;65:420-4.

23. Bergsma TM, Grandjean JG, Voors AA, Boonstra PW, den Heyer P, Ebels T. Low recurrence of angina pectoris after coronary artery bypass graft surgery with bilateral internal thoracic and right gastroepiploic arteries. Circulation. 1998;97:2402-5.

24. Borst C, Grundeman PF. Minimally invasive coronary artery bypass grafting: an experimental perspective. Circulation. 1999;99:1400-3.

25. Loop FD. Coronary artery surgery: the end of the beginning. Eur J Cardiothorac Surg. 1998;14:554-71.

26. Teirstein PS, Massullo V, Jani S, Popma JJ, Mintz GS, Russo RJ, et al. Catheter-based radiotherapy to inhibit restenosis after coronary stenting. N Engl J Med. 1997;336:1697-703.

27. Leon MB, Teirstein PS, Moses JW, Tripuraneni P, Lansky AJ, Jani S, et al. Localized intracoronary gamma-radiation therapy to inhibit the recurrence of restenosis after stenting. N Engl J Med. 2001;344:250-6.

28. The EPISTENT Investigators. Randomized placebo-controlled and balloon-angioplasty-controlled trial to assess safety of coronary stenting with use of platelet glycoprotein-IIb/IIIa blockade. Evaluation of Platelet IIb/IIIa Inhibitor for Stenting. Lancet. 1998;352:87-92.

29. Sousa JE, Costa MA, Abizaid AC, Rensing BJ, Abizaid AS, Tanajura LF, et al. Sustained suppression of neointimal proliferation by sirolimus-eluting stents: one-year angiographic and intravascular ultrasound follow-up. Circulation. 2001;104:2007-11.

\section{Appendix 1}

\section{Organization}

This study was conducted under auspices of the European Academy of Sciences and Arts, patronage: Mr. Jacques SANTER, former President, European Commission in Brussels.

\section{Sponsor}

Cordis Corporation, a Johnson \& Johnson Company, Miami Lakes, Fla.

\section{Safety and Data Monitoring}

Stuart Pocock, professor of medical statistics, London School of Hygiene \& Tropical Medicine; Tom Ryan, professor of medicine, Boston University School of Medicine; and Ken Taylor, professor of surgery, Imperial College of Science, Technology, and Medicine at Hammersmith Hospital.

\section{Board of Governors}

Marvin Woodall (international vice president, Johnson \& Johnson, NJ); Brian Firth (vice president, worldwide medical affairs and health economics, Cordis Corporation, Fla); Felix Unger (professor of cardiac surgery, European Heart Institute, Austria); Patrick Serruys (chair of executive steering committee, professor of interventional cardiology, The Netherlands); and Paul Hugenholtz (past president European Society of Cardiology, The Netherlands).

\section{Executive Steering Committee}

This committee is composed of a subgroup of investigators and representatives of both the sponsor and the coordinating center.

Surgery. Felix Unger, Salzburg, Austria (chair); Lex van Herwerden, Rotterdam, The Netherlands; Friedrich Mohr, Leipzig, Germany; Jochen Cremer, Kiel, Germany; and Gusta Petterson, Copenhagen, Denmark.

Interventional Cardiology. Patrick Serruys, Rotterdam, The Netherlands (chair); Rudiger Simon, Kiel, Germany; William Wijns, Aalst, Belgium; Hans Bonnier, Eindhoven, The Netherlands; Antonio Colombo, Milan, Italy; and Marie-Claude Morice, Antony, France.

Outside representatives. O. Madonna (Cordis Corporation, Fla); and G. A. van Es (Cardialysis BV, The Netherlands).

\section{Critical Event Committee}

J. J. Bredee (The Netherlands); O. Hess (Switzerland); W. J. Morshuis (The Netherlands); and W. Wijns (chair, Belgium).

\section{Angiographic Committee}

M. van den Brand (chair, The Netherlands); B. Rensing (The Netherlands); and C. van de Wiel (The Netherlands).

\section{Electrocardiographic Core Laboratory}

All ECGs collected for the study are assessed by an independent core laboratory located at Cardialysis, Rotterdam, The Netherlands.

\section{Data Coordinating Center}

The Data Coordinating Center is located at Cardialysis, Rotterdam, The Netherlands (H. Hennessey, A. M. Hoogenboom, M. Kuypers, M. A. Morel, and V. de Valk). The trial is being monitored by Parexel (I. Kuit). Data analysis has been carried out by W. Lindeboom.

\section{Appendix 2}

The following institutions and investigators participated in the study (the number of patients enrolled at each center is given in parentheses): Instituto Dante Pazzanese de Cardiologia, Sao Paulo, Brazil (66), J. E. Sousa and A. Jatene; Catharina Ziekenhuis, Eindhoven, The Netherlands (61), J. J. R. M. Bonnier and J. P. A. M. Schönberger; The Queen Elizabeth Hospital, Birmingham, United Kingdom (54), N. Buller and R. Bonser; CHU Sart Tilman, Liège, Belgium (47), V. Legrand and R. Limet; AZR Dijkzigt, Thoraxcentrum, Rotterdam, The Netherlands (47), P. W. Serruys and L. van Herwerden; St Paul's Hospital, Vancouver, Canada (46), R. Carere and S. Lichtenstein; Herzzentrum Leipzig, Leipzig, Germany (43), G. Schuler and F. W. Mohr; Medisch 
Centrum "De Klokkenberg," Breda, The Netherlands (39), P. C. H. Roose and T. R. van Geldorp; Hospital Clinico San Carlos, Madrid, Spain (32), C. Macaya and J. L. Castañon; Landeskliniken Salzburg, Salzburg, Austria (30), G. Heyer and F. Unger; Hospital Universitario de Valladolid, Valladolid, Spain (28), F. FernandezAvilès and J. Herreros Gonzáles; Ziekenhuis De Weezenlanden, Zwolle, The Netherlands (27), H. Suryapranata and M. Haalebos; Onze-Lieve Vrouw Ziekenhuis, Aalst, Belgium (26), W. Wijns and F. Wellens; London Chest Hospital, London (26), United Kingdom, M. T. Rothman, R. Balcon, and J. Wright; Unicor Hospital, Sao Paulo, Brazil (26), E. Ribeiro and E. Buffolo; Rambam Medical Center, Haifa, Israel (25, R. Beyar and S. Milo); Christian Albrechts Universität, Kiel, Germany (25), R. Simon and D. Regensburger; St James's Hospital, Dublin, Ireland (22), P. Crean and E. McGovern; Academisch Ziekenhuis Middelheim, Antwerp, Belgium (21), P. van den Heuvel and C. van Cauwelaert; Vancouver Hospital and Health Science Centre, Vancouver, British Columbia, Canada (20), I. Penn and G. F. O. Tyers; Harefield Hospital, Uxbridge, United Kingdom (19), C. Ilsley and M. Yacoub; Skejby Sygehus, Arhus, Denmark (18), T. Toftegaard Nielsen and P. Kildeberg Paulsen; Onze Lieve Vrouwe Gasthuis, Amsterdam, The Netherlands (17), F. Kiemeney and L. Eysmann; Algemeen Ziekenhuis St Jan, Genk, Belgium (17), M. Vrolix and G. Fransen; Hôpital de la Citadelle, Liège, Belgium (17), P. Materne and G. de Koster; Hospital Santa Cruz, Linda-A-Velha, Portugal (17), R. Seabra-Gomes and J. Queiróz E Melo; Montreal Heart Institute, Montreal, Quebec (17), Canada, L. Bilodeau and M. Carrier; Fundación Favaloro, Buenos Aires, Argentina (16), H. F. Londero and V. Caramutti; Universitair Ziekenhuis Gent, Gent, Belgium (16), Y. Taeymans and G. van Nooten; Herzzentrum Bodensee, Kreuzlingen, Switzerland (16), M. Pieper and D. Maass; Northern General Hospital, Sheffield, United Kingdom (16), D. Cumberland, F. Ciulli, and G. Cooper; Wessex Cardiology Centre, Southampton, United Kingdom (16), K. Dawkins and S. Livesey; Academisch Ziekenhuis Maastricht, Maastricht, The Netherlands (15), F. W. H. M. Biir and K. Prenger; Royal North Shore Hospital of Sydney, Sydney, Australia (15), G. I. C. Nelson and D. Marshman; Hospital Clinic i Provincial, Barcelona, Spain (14), A. Betriu and J. L. Pomar; Academisch Ziekenhuis Groningen, Groningen, The Netherlands (14), A. J. van Boven, P. W. Boonstra; Onassis Cardiac Surgery Center, Athens, Greece (13), V. Voudris and G. Stavridis; Rigshospitalet, Copenhagen, Den- mark (13), K. Saunamäki and K. Sander-Jensen; Centro Hospitalar de Gaia, Vila Nova de Gaia, Portugal (13), V. Gama Ribeiro and M. D. M. S. Guerreiro; Universitätsklinikum Charité, Berlin, Germany (11), W. Rutsch and W. Konertz; Prince Charles Hospital, Brisbane, Australia (11), J. H. N. Bert and P. Tesar; Hôpital Henri Mondor, Créteil, France (11), J. L. Dubois-Rande and D. Loisance; Ospedale di Circolo, Varese, Italy, G. Binaghi and G. Tarelli; Allgemeines Krankenhaus der Stadt Wien, Vienna, Austria (11), P. Probst, E. Wolner, and G. Laufer; I. Medizinische Klinik RWTH Aachen, Aachen, Germany (10), P. Hanrath and B. Messmer; Instituto Malattie Cardiovascolare, Policlinico S. Orsola-Malpighi, Bologna, Italy (10), G. Piovaccari, C. Marrozzini, and G. Marinelli; Hadassah University Hospital, Jerusalem, Israel (10), C. Lotan and G. Merin; Tel Aviv Medical Center, Tel Aviv, Israel (10), S. Braun and R. Mor; Institut Cardiovasculaire Paris-Sud, Institut Hospitalier Jacques Cartier, Massy, France (9), M. C. Morice and P. Donzeau-Gouge; Hôpital Universitaire de Mont Godinne, Yvoir, Belgium (9), E. Schroeder and J. C. Schoevaerdts; Shaare Zedek Medical Center, Jerusalem, Israel (8), D. Tzivoni and D. Bitran; Ospedale Maggiore, Trieste, Italy (8), A. Salvi, L. Dreas, and B. Branchini; Städtische Kliniken Dortmund, Dortmund, Germany (7), B. Lösse and M. J. Polonius; Centre Universitaire Vaudois, Lausanne, Switzerland (7), J. J. Goy and L. K. von Segesser; Academisch Ziekenhuis St Radboud, Nijmegen, The Netherlands (7), H. Gehlmann and S. Singh; Centro Cuore Columbus, Milan, Italy (6), A. Colombo and C. Santoli; Instituto Scientifico H. San Raffaele, Milan, Italy (6), I. Sheiban and O. Alfieri; University Hospital, Zürich, Switzerland (6), T. Lüscher and M. Turina; UCL Saint-Luc, Brussels, Belgium (5), C. Hanet and R. Dion; Universitätsklinikum Rudolf Virchow, Franz-Volhard Klinik, Berlin Buch, Germany (4), D. C. Gulba and B. Schübel; Clinique Générale St Jean, Brussels, Belgium (4), M. Vandormael and P. Bettendorf; Green Lane Hospital, Auckland, New Zealand (3), J. Ormiston, P. Ruygrok, and A. Kerr; Instituto Cardiovascular de Buenos Aires, Buenos Aires, Argentina (3), J. Belardi and D. Navia; Zentrum für Innere Medizin, Universitätsklinikum Essen, Essen, Germany (3), R. Erbel, M. Haude, and J. C. Reidemeister; Academisch Medisch Centrum, Amsterdam, The Netherlands (2), K. Koch and B. A. J. de Mol; Klinikum Grosshadern, Munich, Germany (2), S. Nikol and B. Reichart; and Deutsches Herzzentrum München, Munich, Germany (1), A. Schömig, F. Meisner, and K. Holper. 